\title{
Dry land tree management for improved household livelihoods: Farmer managed natural regeneration in Niger
}

\author{
Eric Haglund ${ }^{\mathrm{a}}$, Jupiter Ndjeunga ${ }^{\mathrm{b}, *}$, Laura Snook ${ }^{\mathrm{c}}$, Dov Pasternak ${ }^{\mathrm{b}}$ \\ ${ }^{a}$ Mickey Leland International Hunger Fellow of the Congressional Hunger Center, 400 North Capitol Street NW Suite G100, Washington, D.C. 20001, USA \\ ${ }^{\mathrm{b}}$ International Crops Research Institute for the Semi-Arid Tropics (ICRISAT), B.P. 12404 Niamey, Niger \\ ${ }^{\mathrm{c}}$ Bioversity International, Via dei Tre Denari 472/a 00057 Maccarese, Italy
}

\section{A R T I C L E I N F O}

\section{Article history:}

Received 28 July 2010

Received in revised form

21 December 2010

Accepted 22 January 2011

Available online 1 April 2011

\section{Keywords:}

Agroforestry

Adoption

Impact

Sahel

Niger

\begin{abstract}
A B S T R A C T
Farmer Managed Natural Regeneration (FMNR), a set of practices farmers use to foster the growth of indigenous trees on agricultural land, has drawn substantial attention as a contributing factor to a trend of increasing vegetation greenness in the Republic of Niger. This paper identifies drivers of FMNR adoption and assesses its impacts on rural households in the Region of Maradi, Niger, an area covering 42,000 square kilometers. The results show that $26 \%$ of households practice a form of FMNR involving both pruning and protecting woody vegetation. Adoption is strongly linked to soil type, market access, and the education level of the head of household. FMNR raises household income and increases crop diversity, household migration rates, and the density and diversity of trees on farmland. It is estimated that FMNR raises the annual gross income of the region by between 17 and 21 million USD and has contributed an additional 900,000 to $1,000,000$ trees to the local environment. These findings support the value of continued promotion of FMNR as an inexpensive means of enhancing rural livelihoods and an attractive alternative to reforestation efforts relying on tree planting.
\end{abstract}

() 2011 Elsevier Ltd. All rights reserved.

\section{Introduction}

Several studies in recent years have described a long-term increase in vegetation greenness in some parts of the African Sahel, contradicting previous assertions of irreversible desertification in the region (Herrmann et al., 2005; Olsson et al., 2005). Increased rainfall appears to have contributed to the Sahelian "re-greening" but these studies suggest rainfall is insufficient to explain the extent of the change in vegetation, positing human-induced changes as a possible explanation. In the Republic of Niger, one of the Sahelian countries where this re-greening has occurred, subsequent research has suggested that widespread changes in farmers' management of the indigenous trees in their fields have resulted in a greater number of trees and improvements in local environmental and agricultural conditions (Abasse et al., 2009; Adam et al., 2006; Larwanou et al., 2006; Reij et al., 2009; UNDP et al., 2008).

This apparent environmental success story has taken place in one of the world's most impoverished nations. In 2008, when the data for this study were collected, Niger's nominal per capita GDP

\footnotetext{
* Corresponding author. Tel.: +227 2072 2626; fax: +227 20734329.

E-mail addresses: eric.r.haglund@gmail.com (E. Haglund), n.jupiter@cgiar.org (J. Ndjeunga).
}

was estimated at 387 US dollars, higher than only 8 other countries (IMF, 2008). ${ }^{1}$ The 2007 Human Development Index (HDI), which combines economic and social indicators, ranked Niger 174 of 179 countries (UNDP, 2007). Niger was one of only seven countries whose hunger severity ranks as "extremely alarming" according to the Global Hunger Index (GHI), a tool developed by the International Food Policy Research Institute (IFPRI) to account for multiple dimensions of hunger and malnutrition (von Grebmer et al., 2008). Numerous statistics and indexes painted a similarly bleak picture.

A prevailing narrative of Niger's anthropogenic re-greening, repeated in multiple international media outlets, describes a scenario in which environmental degradation induced farmers to change their land management practices so as to protect and manage indigenous trees, local environmental conditions improved as tree cover increased, and farmers began to enjoy the benefits of increased crop yields and additional income from tree products (e.g., Harris, 2007; Levett, 2008; Polgreen, 2007; Salopek, 2008). This rendering of events is certainly plausible, and it is consistent with the observations of many individuals who have spent decades witnessing the environmental changes that have occurred in Niger.

\footnotetext{
1 These nominal GDP per capita figures do not account for differences in the cost of living between countries. Niger falls to sixth poorest in the world when GDP per capita is adjusted for purchasing power parity (PPP).
} 
To date, however, much of the evidence underlying this story remains anecdotal and only partially documented. A recent summary of the existing data and literature acknowledged that not all of the indicators of this success story have been "measured with scientific rigor; some were based on farmers' statements and perceptions, and others may not have controlled sufficiently for intervening factors" (Reij et al., 2009, p. 2). Continued research into this story's many intertwined environmental, agricultural, economic, and social aspects is necessary if its success is to be reproduced elsewhere.

The present study seeks to contribute to the discussion by producing and analyzing quantitative data at the household level. We address three key questions. First, how widespread is adoption of the tree conservation and management practices to which Niger's re-greening has been attributed? Second, what factors determine a farmer's likelihood of adopting such practices? And third, what are the impacts of adoption of these practices on household livelihood outcomes? Adoption is assessed using descriptive statistics and probit regression analysis. Impacts are estimated using propensity score matching (PSM) and econometric methods.

In Section 2 we provide background information on farmer managed natural regeneration (FMNR), the name given to the tree management practices analyzed in this study, and in Section 3 we present the analytical framework underlying this analysis. We describe this study's methodology in Section 4 and present results in Section 5, followed by some discussion of the empirical results in Section 6. We conclude by offering some implications of this analysis for policy and research in Section 7 .

\section{Farmer managed natural regeneration}

\subsection{FMNR definition and comparative perspective}

We use the term FMNR to describe the practice of actively managing and protecting non-planted trees and shrubs with the goal of increasing the value or quantity of woody vegetation on farmland. As practiced in Niger, it often involves the selection and pruning of stems growing from the stumps of previously felled trees to encourage the growth of single- or multi-stemmed trees. In some cases farmers protect individual tree seedlings or whole plots of land by constructing makeshift fences. In its more advanced manifestations, FMNR may involve varying forms of coppice management and sometimes pollarding. This kind of active protection and management of tree growth contrasts with previous land management practices whereby farmers cleared all trees from agricultural land before planting (Joet et al., 1998; Rinaudo, 2007). As late as the early 1980s, government extension staff and NGOs were encouraging farmers to remove tree stumps in order to 'modernize' agricultural practices (Abasse et al., 2009).

FMNR is distinct from most afforestation and agroforestry efforts in that it does not require the planting of either seeds or trees but instead makes use of the living rootstocks of previously felled trees that remain in the landscape. Indeed, FMNR was developed largely because of the difficulties involved in raising large numbers of trees in nurseries and ensuring their survival once planted in fields (Abasse et al., 2009; UNDP et al., 2008). Living tree stumps are therefore a necessary prerequisite to the practice of FMNR, and the apparent widespread adoption of FMNR in Niger suggests that the country had considerable tree cover in the past on areas currently used for crop production and grazing, raising questions as to what led to the felling of these trees in recent times.

Previous studies in Niger have applied a variety of labels to these practices that protect residual trees or sprouts, including "improved clearing" (Joet et al., 1998), "assisted tree regeneration" (Boffa,
1999), "modern clearing" and "new modern clearing" (Cunningham and Abasse, 2005), "assisted natural regeneration" or ANR (Adam et al., 2006; Larwanou et al., 2006), and "farmer managed natural regeneration" or FMNR (Rinaudo, 2007; UNDP et al., 2008). Whether these are synonyms or distinct variations is not entirely clear, but all of these terms refer to a similar basic practice. The ambiguous terminology is due at least in part to the multiple languages used in the research. These studies have been written in both English and French, communicating information gathered in local languages, principally Hausa. Another likely source of confusion is the fact that the practice lies at the intersection of agriculture and forestry. Observing the same phenomenon, an agriculturalist may identify a form of "farmer management" of land while a forester sees primarily the "natural regeneration" of trees.

The term ANR seems to be more firmly rooted in the forestry tradition and occurs in the literature on reforestation efforts in Asia. Scientists in the Philippines were among the first to label and describe ANR, which they recommend as a technique to reforest Imperata grasslands (Friday et al., 1999). Citing the Philippines example, FAO began promoting ANR more widely in Southeast Asia as a means of forest rehabilitation and restoration and convened a workshop to highlight ANR's potential in 2002 (Dugan et al., 2003).

Similar language notwithstanding, the ANR examples from Southeast Asia are clearly distinct from the object of the present study. They occur in climatic conditions quite different from those of the Sahel and refer to the regeneration of forests, whereas the practice we observe in Niger entails the regeneration of a selected number of individual trees. Moreover, the Asian examples of ANR have nothing to do with agriculture. The Nigerien case involves the active encouragement of tree growth in farmers' fields. The term "farmer managed natural regeneration" therefore succinctly captures the distinction between ANR and the practice we examine in this study.

Efforts to protect land, restore biodiversity, and benefit farmers through agroforestry have been extensively promoted and studied. The literature on the adoption of agroforestry techniques such as FMNR is voluminous and difficult to summarize except in the broadest of terms. Pattanayak et al. (2004) review 120 articles on the adoption of agricultural and forestry technology by small holders and perform meta-analysis on a subset of 32 studies on agroforestry and related investments primarily from tropical areas. They conclude that risk, bio-physical, and resource factors are the most likely determinants of adoption. FMNR is distinct from most agroforestry techniques in that it relies wholly on encouraging the growth of living indigenous trees and requires no nursery-raising or planting. Since the technique of FMNR is quite unusual in this regard, it is unclear how applicable the results of other agroforestry adoption studies are to the case at hand.

\subsection{FMNR in Niger}

\subsubsection{Origins and historical overview}

The present study focuses on Niger's Maradi region because it is the region with the longest history of FMNR promotion and practice. ${ }^{2}$ By the time of Niger's severe droughts and famines in the 1970s, a number of humanitarian and development agencies had recognized a trend of environmental degradation in the Sahel that portended a grim future unless current patterns of deforestation

\footnotetext{
${ }^{2}$ The history of FMNR presented in this section follows the account presented in UNDP et al. (2008). That report draws largely on interviews with several of the individuals involved in the development and promotion of FMNR as well as accounts previously published as project reports and discussion papers.
} 
and unsustainable land use could be altered. At that time, efforts to combat this desertification consisted mostly of raising large numbers of exotic tree species in nurseries then planting them in fields and on degraded land. A host of difficulties bedeviled these reforestation projects, including the high costs of raising seedlings in nurseries and high mortality rates among trees once planted out (UNDP et al., 2008; Abasse et al., 2009).

In 1983 an international aid and missionary organization called Society of International Ministries (SIM, subsequently renamed as Serving in Mission) began promoting FMNR as a component of its Maradi Integrated Development Project (MIDP). When drought and famine struck the region in 1984 and 1988, MIDP included FMNR as part of a Food for Work program. This program was extended to 95 villages in the districts of Dakoro, Guidan Roumdji, and Madarounfa, and exposed an estimated 80,000 to 100,000 farmers to FMNR.

Other organizations had joined MIDP in promoting FMNR by the mid-1990s. Notably, the International Fund for Agricultural Development (IFAD) financed two consecutive initiatives in Maradi's Aguié district of which FMNR was a key activity: the Projet de Développement Rural de l'Arrondissement d'Aguié (PDRAA) and subsequently the Projet de Promotion de l'Initiative Locale pour le Développement à Aguié (PPILDA). The practice of FMNR has spread well beyond the borders of the Maradi region and today agents of the governmental environmental and agricultural services are promoting FMNR along with a host of NGOs.

\subsubsection{Documentation and analysis}

Joet et al. (1998) appear to have been among the first to note a widespread behavior change in the management of shrub and tree resources among Maradi's rural population in their description of "improved clearing". In response to a local scarcity of wood, they report, farmers began protecting the tree shoots that occur naturally during the long dry season rather than removing them during land preparation for the next growing season. Shortly thereafter, in 1999, an MIDP evaluation of villages targeted by the program and villages outside the program reported that $88 \%$ of respondents practiced some degree of FMNR in their fields (USAID et al., 2002). These early studies attest to the fact that FMNR was widely practiced by the late 1990s, but they used small and potentially biased samples of farmers that are not necessarily representative of the broader population.

In the context of his broader analysis of sub-Saharan Africa's agroforestry parklands, Boffa (1999) describes a practice of "encourag[ing] farmers to identify, protect and stimulate the growth of naturally regenerating shrubs and trees in their fields," to which he applies the label "assisted tree regeneration". Boffa's assisted tree regeneration is effectively indistinguishable from what we call FMNR, but we elect to retain the FMNR label because, as noted in Section 2.1 above, we believe the term FMNR properly emphasizes the agricultural aspect of the practice. Boffa recommends the practice as one of a set of techniques for improved management of the Sahel's parklands, and offers the example of Maradi as a successful case. He cites among its advantages the ease and low cost of implementation, the relatively rapid production of wood, and the salutary effects of trees on agricultural conditions.

Adam et al. (2006), as part of a national assessment of the impacts of investments in land management in Niger, estimate that FMNR occurs on over 3 million hectares of farmland, and that it confers a number of environmental and economic benefits. The study was very broad in scope (it collected data from 16 villages in three regions of Niger and was intended to analyze impacts of natural resource management investments in general, of which FMNR promotion was only one) and not designed to produce data for rigorous empirical analysis at the household level. Thus it does not offer the specific information necessary to evaluate the extent and impact of adoption.

Larwanou et al. (2006) use impromptu village meetings and semi-structured interviews for a rapid gathering of information focused specifically on FMNR in three districts of Niger's Zinder region. Their report offers several explanations for the widespread adoption of the practice. Farmers appear to have been motivated by the ecological crises of the 1970s and 1980s to better protect their local natural resources. Around the same time, national policies began to focus on reversing the trend of desertification. The various reforestation and environmental protection initiatives resulting from the policy emphasis on combating desertification may have convinced the population of the value of protecting the trees on their agricultural land. Additionally, increasing population pressure induced farmers to intensify their production, which they did in part by practicing FMNR. The study identified a number of positive impacts resulting from widespread FMNR, including increased incomes through the sales of tree products, improved environmental conditions by reducing wind erosion, increased agricultural productivity through improvements in the soil, improved livestock production through an increase in forage, improved food security (especially via the sale of wood products during the hungry season), improved nutrition, and positive effects on women (who have less difficulty gathering fuel wood) and youths (who have less need to migrate seasonally in search of work because of the additional employment opportunities provided by the cutting and transportation of wood).

Reij et al. (2009) marshal the previous studies of FMNR and argue that Niger's success with FMNR constitutes part of a "different kind of green revolution": a larger, farmer managed, agro-environmental transformation of the Sahel occurring over the past three decades. Citing more recent data than Adam et al. (2006), they estimate that FMNR occurs across 5 million hectares of land in Niger. Their analysis emphasizes the importance of the partnerships and coalitions of actors that were instrumental in bringing about the described transformation, drawing lessons for future agricultural development partnerships.

\section{Analytical framework}

This analysis utilizes a sustainable rural livelihoods (SRL) framework (Fig. 1). The SRL framework is not a formal theory, but rather a holistic approach to understanding poverty in terms of rural livelihoods. It takes a multidisciplinary perspective, drawing on economic, anthropological, sociological, and development theory research relating to household dynamics, gender, governance, and farming systems (Farrington et al., 1999; Scoones, 1998). Like other multidimensional measures of poverty (e.g. Gönner et al., 2007), SRL recognizes the limitations of assessing poverty in terms of a single variable such as income or wealth.

According to the SRL framework, rural households live in a particular (often vulnerable) context, and rely on a stock of livelihood assets consisting of human, physical, social, financial, and natural capital. Households transform these assets through the available structures and processes into livelihood strategies in order to achieve positive livelihood outcomes.

A household's stock of human capital represents the skills, knowledge, ability to work, and good health necessary to the pursuit of different livelihood strategies. Physical capital represents basic physical infrastructure (e.g., shelter, transportation, energy, and communications) and the productive equipment that enables people to pursue livelihood activities. Social capital represents the social resources upon which people draw in pursuit of livelihoods including networks, associations, relationships of trust, and access to social institutions. Financial capital represents the financial 


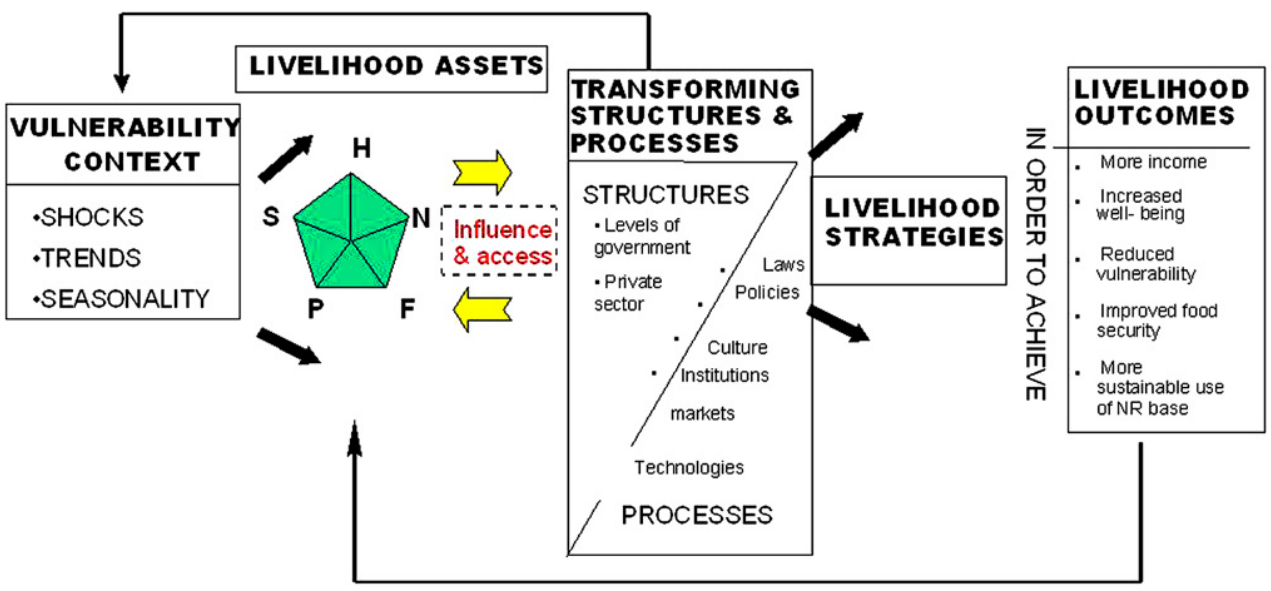

Fig. 1. Modified DFID sustainable livelihood framework.

resources people have available to them such as savings, access to credit, remittances or pensions, that provide them with different livelihood options. Natural capital represents the stock of available natural resources from which livelihoods can be derived including land, water, wildlife, forests, and biodiversity.

A household transforms these livelihood assets through structures and processes (e.g. markets, government, policies, technologies) into its own strategies of pursuing improved livelihood outcomes such as health, income, reduced vulnerability, greater food security, and more sustainable use of natural resources.

The application of the SRL framework to the present analysis is as follows: FMNR is a technology that is available to farmers and its adoption is a livelihood strategy aimed at improving livelihood outcomes. Adoption of the technology will depend on a household's stock of livelihood assets and its particular circumstances in terms of transformational structures and processes. The impact of the technology is assessed in terms of how effectively it enables a household to transform its livelihood assets into improved livelihood outcomes.

\section{Methodology}

\subsection{Description of the study area}

Maradi is one of seven rural administrative regions of Niger. It is positioned in south-central Niger along the border with Nigeria. Maradi covers an area of about $41,796 \mathrm{~km}^{2}$ and hosts a population of 2,865,219 (2008 estimate), making it the most densely populated of Niger's regions (INS, 2008). That population is estimated to be growing at an annual rate of $3.59 \%$, compared to a rate of $3.10 \%$ for the country as a whole. At this rate, the population of Maradi would be expected to double in less than 20 years. The region comprises six départements or districts: Aguié, Dakoro, Guidan Roumdji, Madarounfa, Mayahi, and Tessaoua.

The city of Maradi was once considered the economic capital of Niger, largely because the region was and remains among Niger's most agriculturally productive areas. ${ }^{3}$ Among the major crops, $18 \%$ of Niger's millet, $20 \%$ of its sorghum, $21 \%$ of its cowpea and $38 \%$ of its groundnuts are produced in Maradi. Between 600 and $800 \mathrm{~mm}$ of rain per year may fall in the region's southern zones, while the far north can only expect annual precipitation of $200-400 \mathrm{~mm}$. Like

\footnotetext{
3 The agricultural production statistics have been drawn from the Maradi description in Pender and Ndjeunga (2008).
}

much of Niger, the majority of Maradi's soils are sandy Arenosols containing very little organic matter.

The population of Maradi is predominantly ethnic Hausa (83\%), while Peulh and Tuareg make up, respectively, 10 and $6 \%$ of the population. Maradi was one of the regions severely impacted in Niger's much publicized local food crisis of 2005-2006.

\subsection{Sample design and data collection}

Secondary data from a database developed by the Institut Géographique du Niger (IGN) were used to stratify all villages in the Maradi region according to market access (greater or less than $6 \mathrm{~km}$ from village) and agro-climatic zone (growing period of greater or less than 75 days). These two stratification variables were selected to ensure adequate representation of more remote and drier regions. Additionally, project documents and discussions with NGO representatives, project staff, and the Maradi regional office of the Government of Niger's Ministère de l'Environnement et de Lutte Contre la Désertification (ME/LCD) were used to compile a list of villages where FMNR had been formally promoted by a program or project. These were designated as "program" and "non-program" villages. The sample of 41 villages to be surveyed was drawn according to the proportion of Maradi's villages found in each stratum. Within each stratum, an equal number (or as close to equal as possible when there were an odd number of villages) of program and non-program villages were selected at random.

Ten households in each village were selected by random draw for a detailed interview. ${ }^{4}$ Upon arrival in the village, the survey enumerators compiled with the help of the village chief a list of all the households in the village. At a village meeting with all heads of household present, numbers were drawn at random to select name from the list. This process served to minimize bias in the selection of households within the village. Overall, 410 households participated.

The structured survey was implemented during the month of April, 2008. In each village, survey interviews were carried out at

\footnotetext{
${ }^{4}$ Researchers familiar with this part of the world have found it problematic to perform these kinds of analyses at the level of the "household", given the complexities of polygamous and broadly-defined families. The "production unit" is an often used alternative, defined as family members who work together in the same fields. The distinction between this and other common definitions of the household (e.g., that used by the FAO) is that the production unit is defined by the sharing of productive resources rather than the sharing of consumption goods. Throughout this discussion, household and production unit should be considered as synonymous.
} 
both the village and household level. First, a village meeting was called at which a village questionnaire was completed and the 10 households to be surveyed were selected. An average of 18 people participated in each meeting but the size ranged from 12 to 60 participants. The village questionnaire collected information about access to markets, local infrastructure and services, programs and organizations in the village, local prices for crops, livestock, and tree products, land tenure systems, and perceptions of changes in local conditions and the reasons for change.

Household surveys were conducted with the head of household whenever possible. The questionnaire collected information about household demographic characteristics, endowments of human, physical, social, financial, and natural capital, food security, FMNR knowledge and practice, agricultural plot characteristics, land and tree tenure and rights, tree preferences, and revenues and expenditures occurring over the past year. These village and household data were entered into databases where they were collated and checked for errors.

\subsection{Data analysis}

\subsubsection{FMNR adoption}

A crucial first step of this analysis is the selection of our operational definition of FMNR. Larwanou et al. (2006) define FMNR as "when farmers actively protect and manage the new growth in their fields in order to (re)create woody vegetation" (p. 1). Other definitions of FMNR tend to refer to the more specific management practice of pruning the shoots growing from the stumps of previously felled trees. Therefore, we determine that it is necessary that our definition of FMNR include some combination of protection and management of trees. The survey data allow us to do this using two questions that asked whether farmers deliberately encourage the growth of trees on their farmland (i) by pruning and (ii) by protecting young trees. Any respondent who answered yes to both of these questions was identified for our purposes as an FMNR practitioner. Although the protection and management questions were asked separately about each of a farmer's fields, very few farmers in our sample reported varying the practices between fields. The questions concerning the practices that we define as FMNR adoption were posed with respect to the current year. Therefore, the results reported in Section 5 do not capture the impact of having practiced FMNR over a longer or shorter period of time.

Basic descriptive statistics are presented in order to examine the prevalence of adoption and observable differences between adopting and non-adopting households. The mean and standard deviation for each statistic is reported. For categorical variables we report proportions under each category. This section provides a brief profile of the typical household in the survey population.

Following the descriptive analysis, adoption is assessed using a probit regression analysis. The probit model is given as:

$p\left(Y_{i}=1\right)=F\left(\sum \beta_{k} X_{i k}\right)$

where $p$ is the probability, $Y_{i}$ is a binary variable equal to 1 if a household practices FMNR and 0 otherwise, $F$ is the cumulative density function, $X_{i}$ represents a vector explanatory variables and $\beta$ the coefficients of the parameters. It follows from our analytical framework that we seek to explain adoption in terms of a households stock of livelihood assets and the transformational structures and processes that apply to it. However, the selection of explanatory variables for inclusion in the probit models is complicated by the high potential for endogeneity when using variables measured after adoption of FMNR. For this reason, the probit model used here is limited to variables that could plausibly have influenced the likelihood of adoption, but could not have been influenced by the adoption decision.

The probit model estimating the likelihood of adoption uses the following variables: length of growing period (shorter or longer than 75 days per year); soil type (sandy or non-sandy); distance to nearest market in $\mathrm{km}$; age of the head of household; years of education of the head of household; total household land holdings (in hectares); sex of the head of household, and living in a program or non-program village. Table 1 provides a complete list of variables and definitions.

\subsubsection{Impacts of adoption on livelihood outcomes}

We evaluate the impact of FMNR adoption by estimating adoption's effect on household income, food security, and condition of the local natural resource base. These livelihood outcomes, and the specific variables used to measure them, were selected based on previously reported assertions of FMNR's impacts on adopting households (e.g. Larwanou et al., 2006; Rinaudo, 2007; UNDP et al., 2008).

Income. This analysis measures income using gross income per capita, defined as the sum total value of crop and wood production, agricultural wage income, and any non-farm income, adjusted per capita using adult equivalent units (AEU). The natural log of gross income per capita was used as well, which reduces the potential problems caused by outliers and heteroskedasticity (Mukherjee et al., 1998).

Food security. As food security is an imprecise notion, we use several proxy variables. First, we consider cereal production per capita, calculated as the total number of kilograms of millet, sorghum and maize divided by household size adjusted for AEU. Survey respondents were also asked how many months of the year they typically have trouble finding enough to eat. This measure of "food shortage" offers a second proxy variable for food security. Thirdly, we considered crop diversity, as measured by the number of crops grown per farm, under the assumption that a more diverse portfolio of crops is likely to reduce vulnerability to shocks. Finally, as migration is often interpreted as a response to a lack of resources

Table 1

Complete list of variables and definitions.

\begin{tabular}{ll}
\hline Variable & Definition \\
\hline Household and farm variables \\
AGE & Age of household head in years \\
HH SIZE & Size of household in individuals \\
HH AEU & Size of household in adult equivalent units (AEU) \\
ED READ & 1 if head of household can read (in any language), 0 otherwise \\
ED WRITE & 1 if head of household can write (in any language), 0 otherwise \\
ED YEARS & Years of formal, modern education of the head of household \\
FEMALE & 1 if head of household is female, 0 otherwise \\
HAUSA & 1 if head of household is ethnic Hausa, 0 otherwise \\
MIGRANTS & Number of household members migrating in past year \\
ASSETS CAP & Total value of household assets per cap (using AEU) \\
GRS INC CAP & Household gross income per capita (using AEU) \\
LOG INC CAP & Natural log of household gross income per capita \\
PCT NONCER & Percent of household income derived from non-cereal crops \\
FARMSIZE & Total farm size in hectares \\
CEREALS & Cereal production per capita (using AEU) in kg \\
FOODSHORT & Number of months of food shortage in past year \\
CROP DIV & Number of crops grown on the farm \\
TREEDENS & Number of trees per hectare of farmland \\
TREEDIV & Number of tree species per farm \\
Village variables & \\
LGP > 75 & Length of growing period greater than 75 days per year \\
NON SAND & 1 if local soil type is other than Arenosol, 0 if arenosol \\
MKT DIST & Distance to nearest market in km \\
MKT DIST^2 & Square of the distance to market \\
PROGRAM & 1 if FMNR formally promoted in village, 0 otherwise \\
\hline
\end{tabular}


and employment opportunities at home, we used the number of migrants per household.

Condition of local natural resource base. Two variables are used to proxy for the condition of natural resources available to households: the density of woody vegetation, defined as the number of individual trees per hectare of a household's farmland, and the diversity of woody species, defined as the number of different woody species represented on the farm.

The impact of FMNR adoption, or the average effect of the treatment on the treated (ATT), is given by the equation:

$$
\mathrm{ATT}=E\left(Y_{1} \mid p=1\right)-E\left(Y_{0} \mid p=1\right)
$$

where $p=$ FMNR adoption ( $p=1$ if adopted FMNR and $p=0$ if did not adopt); $Y_{1}=$ outcome of the household after adoption; $Y_{0}=$ outcome of the same household if they had never adopted FMNR; and $E($ ) refers to expected value. While the first term in the expression, $E\left(Y_{1} \mid p=1\right)$, is observable, the second, $E\left(Y_{0} \mid p=1\right)$, is not, illustrating the fundamental problem in estimating the impact of FMNR adoption: the lack of an obvious counterfactual for adopting households. We address this problem by using propensity score matching (PSM) to compare FMNR adopters only to the nonadopters whom they most closely resemble in terms of observable characteristics (Rosenbaum and Rubin, 1983).

Propensity scores were calculated using the probit model described in Section 4.3.1 and several matching algorithms were employed. Different matching methods involve trade-offs between bias and efficiency, though as the sample size and match quality increase the differences are reduced (Caliendo and Kopeinig, 2008). To test the sensitivity of our results to the matching method used, we use both nearest neighbor matching and kernel matching. ${ }^{5}$ Our matching procedure also imposed "common support", automatically dropping observations having propensity scores that are smaller than the minimum and larger than the maximum in the opposite group. A potential drawback of imposing common support is that dropping too many observations can decrease efficiency by effectively reducing the sample size. In our calculations only 41 observations (of 410) were dropped due to common support, so the loss of efficiency is likely to be minimal.

Poor matches will bias the PSM results. To test for the quality of the matches we test for differences in covariate means between adopters and non-adopters in the unmatched and matched samples. These balancing tests reveal that differences in covariate means between adopters and non-adopters are almost universally reduced after matching, revealing that the matching procedure reduces biases as intended. However, some statistically significant differences remain in the matched samples, so we cannot fully eliminate the possibility of biases.

To address these remaining concerns about biases in the PSM results, we include a third matching procedure that matches using $\mathrm{N}$ nearest neighbors and corrects for bias using auxiliary regressions and estimates the analytically correct standard error for the ATT (Abadie et al., 2004). ${ }^{6}$ The drawback to this estimator is that it does not account for the fact that different matching covariates have unequal strength in predicting the probability of FMNR adoption and instead uses a more arbitrary distance metric.

As a final method of checking the robustness of the PSM results, this analysis estimated the impact of FMNR adoption econometrically using a simple OLS linear regression model. The value of each outcome variable was estimated based on the same set of

\footnotetext{
${ }^{5}$ By default, STATA uses an Epanechnikov kernel for this procedure.

6 We used the five nearest neighbor matches using the NNMATCH command in STATA.
}

explanatory variables used to estimate the propensity scores in the PSM model plus and indicator variable for FMNR adoption. The coefficient on the FMNR indicator variable represents the econometric model's estimate of the treatment effect. These linear regressions were tested for multicollinearity but there appears to be no cause for concern. The only variance inflation factors (VIF) above 1.21 were those for market distance and market distancesquared, which would necessarily be highly correlated with each other.

\section{Results}

\subsection{Characteristics of the sample population}

Table 2 summarizes selected descriptive statistics for the sample population as well as the subsets of adopters and non-adopters. Twenty-six percent of households are FMNR adopters according to our definition of adoption as both pruning and protection of trees with the goal of fostering their growth. Ninety-three percent of households practice pruning, while only $26 \%$ practice protection (only a single household reported protection without pruning). Fifty-nine percent of households live in a village where FMNR has been formally promoted.

The mean household is made up of 11 individuals, including a 44 year old head of household with 1.8 years of education and more than 6 children under the age of 16 . Ninety-three percent of households identify themselves as ethnic Hausa and less than two percent are female-headed. Respondents report experiencing difficulty getting enough to eat for an average of 3.9 months of the year. The average annual gross income per capita is 66445 FCFA (about 133 USD). ${ }^{7}$ The typical farm produces four crops (millet, sorghum, cowpea, and groundnut being, respectively, the most common) and covers an area of 9.3 hectares. An average of eight tree species is found per farm, occurring at a density of 32 individual trees per hectare.

The descriptive statistics reveal several differences between FMNR adopters and non-adopters. Adopting households are more likely to be female-headed, more likely to be able to read and write, and have received more schooling. Adopters tend to live farther from markets and disproportionately on non-sandy soils. Adopters also appear to enjoy better economic circumstances than nonadopters, with greater incomes, larger stocks of assets, and greater cereal production. They also grow a more diverse mix of crops and have a greater diversity and density of trees on their farms.

\subsection{Determinants of adoption}

Table 3 presents the result of the probit regression model estimating the determinants of FMNR adoption. Three variables appear to significantly affect the probability of adoption: soil type, market distance, and the education level of the head of household. Notably, this analysis shows no significant impact on the probability of FMNR adoption associated with living in a village where FMNR has been promoted by a project or program.

Living in a non-Arenosol area is associated with a $27 \%$ greater likelihood of practicing FMNR. The relationship between FMNR adoption and the distance to the nearest market is nonlinear and concave, as indicated by the fact that the coefficients on distance and distance-squared are both highly significant. The probability of a household being an FMNR adopter increases with distance from market town until a distance of about $15 \mathrm{~km}$, after which it

\footnotetext{
7 Conversions between FCFA and USD here and elsewhere use an exchange rate of 500 FCFA per 1 USD.
} 
Table 2

Selected characteristics of the complete sample, FMNR adopters, and non-adopters.

\begin{tabular}{|c|c|c|c|c|c|c|}
\hline \multirow[t]{2}{*}{ Variable } & \multicolumn{2}{|l|}{ Sample } & \multicolumn{2}{|c|}{ FMNR adopters } & \multicolumn{2}{|c|}{ FMNR non-adopters } \\
\hline & Mean & S.D & Mean & S.D. & Mean & S.D. \\
\hline \multicolumn{7}{|l|}{ FMNR variables } \\
\hline Pruning & 0.93 & 0.26 & 1.00 & 0.00 & 0.90 & 0.30 \\
\hline Protection & 0.27 & 0.44 & 1.00 & 0.00 & 0.00 & 0.06 \\
\hline Prune \& protect & 0.26 & 0.44 & 1.00 & 0.00 & 0.00 & 0.00 \\
\hline \multicolumn{7}{|l|}{ Household variables } \\
\hline AGE & 44.47 & 14.07 & 44.47 & 13.46 & 44.47 & 14.30 \\
\hline HH SIZE & 11.03 & 6.21 & 11.23 & 6.27 & 10.96 & 6.20 \\
\hline HH AEU & 6.09 & 3.75 & 6.18 & 3.60 & 6.06 & 3.81 \\
\hline ED READ & 0.43 & 0.50 & 0.62 & 0.49 & 0.36 & 0.48 \\
\hline ED WRITE & 0.40 & 0.49 & 0.59 & 0.49 & 0.33 & 0.47 \\
\hline ED YEARS & 1.78 & 3.55 & 3.13 & 4.44 & 1.30 & 3.04 \\
\hline FEMALE & 0.01 & 0.11 & 0.03 & 0.17 & 0.01 & 0.08 \\
\hline HAUSA & 0.93 & 0.25 & 0.92 & 0.28 & 0.94 & 0.24 \\
\hline MIGRANTS & 0.61 & 0.84 & 0.63 & 0.79 & 0.60 & 0.86 \\
\hline ASSETS CAP & 275,698 & 219,207 & 311,830 & 247,295 & 262,759 & 207,156 \\
\hline GRS INC CAP & 66,445 & 61,635 & 83,124 & 85,863 & 60,607 & 49,363 \\
\hline PCT NONCER & 0.44 & 0.24 & 0.48 & 0.22 & 0.42 & 0.24 \\
\hline FARMSIZE & 9.32 & 7.67 & 8.57 & 5.42 & 9.58 & 8.32 \\
\hline CEREALS & 163.77 & 172.92 & 189.03 & 229.90 & 154.93 & 147.36 \\
\hline FOODSHORT & 3.92 & 1.65 & 3.95 & 1.64 & 3.91 & 1.65 \\
\hline CROP DIV & 4 & 1 & 4 & 1 & 3 & 1 \\
\hline TREEDENS & 32 & 35 & 42 & 45 & 29 & 29 \\
\hline TREEDIV & 8 & 4 & 9 & 4 & 7 & 4 \\
\hline \multicolumn{7}{|l|}{ Village variables } \\
\hline LGP $>75$ & 0.66 & 0.47 & 0.62 & 0.49 & 0.67 & 0.47 \\
\hline NON SAND & 0.15 & 0.35 & 0.23 & 0.42 & 0.12 & 0.32 \\
\hline MKT DIST & 7.16 & 4.38 & 9.29 & 4.43 & 6.40 & 4.12 \\
\hline PROGRAM & 0.59 & 0.49 & 0.66 & 0.48 & 0.56 & 0.50 \\
\hline$N$ & 410 & & 108 & & 302 & \\
\hline Percent of sample & 100 & & 26 & & 74 & \\
\hline
\end{tabular}

Variable definitions explained in Table 1.

decreases. The education level of the head of household is also a highly significant predictor of adoption, with the probability of adoption increasing by $2.8 \%$ with every year of schooling.

\subsection{Impacts of adoption}

The PSM and econometric estimates of the impacts of FMNR adoption are summarized in Table 4. All four estimation methods show a significant, positive impact of FMNR adoption on (unlogged) per capita gross income, crop diversity, tree density, and tree diversity above the 95\% significance level. Impacts on the natural log of gross income per capita and migrants per household are also positive and significant at the $90 \%$ significance level for three of the four matching methods (in both cases the exception is

Table 3

Results of FMNR adoption probit model.

\begin{tabular}{lcl}
\hline \multicolumn{2}{l}{ Dependent variable: adoption of FMNR } & \\
\hline Independent variable & Marginal effect & Standard error \\
\hline AGE & 0.0022 & 0.0016 \\
FEMALE & 0.3185 & 0.2424 \\
ED YEARS & $0.0280^{* * *}$ & 0.0062 \\
MKT DIST & $0.0830^{* * *}$ & 0.0185 \\
MKT DIST^2 & $-0.0027^{* * *}$ & 0.0009 \\
LGP > 75 & 0.0571 & 0.0520 \\
NON SAND & $0.2709^{* * *}$ & 0.0840 \\
PROGRAM & -0.0013 & 0.0487 \\
FARMSIZE & -0.0034 & 0.0032 \\
Pseudo- $R^{2}$ & 0.1658 & \\
$N$ & 410 & \\
\hline
\end{tabular}

Variable definitions explained in Table 1.

${ }^{*} p<0.10,{ }^{* *} p<0.05,{ }^{* * *} p<0.01$. the bias-adjusted NN matched estimate). The econometric estimate of cereal production per capita is positive and significant at the $90 \%$ level, but none of the matched estimates reveal a significant impact on this variable. The bias-adjusted NN estimate of the number of months of food security is positive and highly significant, but this result does not occur elsewhere.

Our best estimates indicate that FMNR adoption increases gross annual household income by between 22,805 and 27,950 FCFA (46 and 56 USD) per capita. According to the three significant estimates of the natural log of this variable, adoption increases income by $18-24 \%$. Adopters grew an average of almost four crops on their farms while their matched non-adopters grew just over three, suggesting that adoption increases crop diversity. Adoption also appears to increase tree diversity by between one and three tree species per farm, and increase tree density by between 12 and 16 trees per hectare.

\section{Discussion}

The results of this analysis strongly support the notion that FMNR is widely practiced in the Region of Maradi and confers significant benefits at the household level. Extrapolating from these results and the available demographic data, we estimate that roughly 62,000 households in the region of Maradi practice FMNR according to our more complete definition of pruning and protection, raising the total gross income of the region by between 17 and 21 million USD per year and contributing an additional 900,000 to 1 million trees to the local environment.

We attribute the widespread adoption of FMNR to the fact that its benefits are obtainable at minimal costs to the farmer. The practice requires no expenditures beyond the farmer's additional labor. A commonly used rule holds that the ratio of benefits to costs 
Table 4

Impacts of FMNR adoption estimated by matching and econometric methods.

\begin{tabular}{|c|c|c|c|}
\hline Variable & Estimation method & $\begin{array}{l}\text { Estimated impact } \\
\text { of FMNR adoption }\end{array}$ & $\begin{array}{l}\text { Estimated } \\
\text { standard error }\end{array}$ \\
\hline \multirow[t]{4}{*}{ GRS INC CAP } & Nearest neighbor matching & $+27,950^{* * *}$ & 10,794 \\
\hline & Kernel matching & $+23,108^{* *}$ & 10,320 \\
\hline & Bias-adjusted NN matching & $+22,805^{* *}$ & 9456 \\
\hline & Econometric estimation & $+25,388^{* * *}$ & 7458 \\
\hline \multirow[t]{4}{*}{ LOG INC CAP } & Nearest neighbor matching & $+0.2414^{*}$ & 0.1279 \\
\hline & Kernel matching & $+0.1823^{*}$ & 0.1068 \\
\hline & Bias-adjusted NN matching & +0.1670 & 0.1029 \\
\hline & Econometric estimation & $+0.2279^{* *}$ & 0.0921 \\
\hline \multirow[t]{4}{*}{ CEREALS } & Nearest neighbor matching & +37.98 & 32.88 \\
\hline & Kernel matching & +43.03 & 28.28 \\
\hline & Bias-adjusted NN matching & +31.47 & 24.87 \\
\hline & Econometric estimation & $+40.10^{*}$ & 20.49 \\
\hline \multirow[t]{4}{*}{ FOODSHORT } & Nearest neighbor matching & +0.13 & 0.29 \\
\hline & Kernel matching & +0.27 & 0.23 \\
\hline & Bias-adjusted NN matching & $+0.64^{* * *}$ & 0.22 \\
\hline & Econometric estimation & +0.12 & 0.20 \\
\hline \multirow[t]{4}{*}{ CROP DIV } & Nearest Neighbor matching & $+0.46^{* * *}$ & 0.17 \\
\hline & Kernel matching & $+0.40^{* * *}$ & 0.12 \\
\hline & $\begin{array}{l}\text { Bias-adjusted NN } \\
\text { matching }\end{array}$ & $+0.48^{* * *}$ & 0.14 \\
\hline & Econometric estimation & $+0.58^{* * *}$ & 0.13 \\
\hline \multirow[t]{4}{*}{ MIGRANTS } & Nearest neighbor matching & $+0.25^{*}$ & 0.14 \\
\hline & Kernel matching & $+0.20^{*}$ & 0.11 \\
\hline & Bias-adjusted NN matching & +0.04 & 0.10 \\
\hline & Econometric estimation & $+0.18^{*}$ & 0.10 \\
\hline \multirow[t]{4}{*}{ TREEDENS } & Nearest neighbor matching & $+16.10^{* *}$ & 6.56 \\
\hline & Kernel matching & $+14.80^{* * *}$ & 5.57 \\
\hline & Bias-adjusted NN matching & $+11.75^{* *}$ & 4.82 \\
\hline & Econometric estimation & $+15.38^{* * *}$ & 4.17 \\
\hline \multirow[t]{4}{*}{ TREEDIV } & Nearest neighbor matching & $+2.53^{* * *}$ & 0.72 \\
\hline & Kernel matching & $+1.80^{* * *}$ & 0.53 \\
\hline & Bias-adjusted NN matching & $+1.27^{* *}$ & 0.51 \\
\hline & Econometric estimation & $+2.31^{* * *}$ & 0.45 \\
\hline
\end{tabular}

Variable definitions explained in Table 1.

${ }^{*} p<0.10,{ }^{* *} p<0.05,{ }^{* * *} p<0.01$.

of an agricultural innovation must be at least two in order to induce adoption (CIMMYT, 1988). Using information from the survey data on the labor required for FMNR and the daily wage for agricultural labor, we estimate the annual benefit-cost ratio of practicing FMNR at between 2.5 and 3.0 .

The income gains associated with FMNR appear to result from increases in the value of crop and wood production. Although the estimated impact on cereal production suggests that FMNR does not significantly increase grain yields, the increase in the value of crop production may result from greater yields from other crops such as cowpea and groundnut. Furthermore, since FMNR appears to increase crop diversity, it may be that FMNR raises income by enabling farmers to diversify into higher value crops, increasing the value of crop production without increasing the yield of any particular crops.

The figures reported in Table 4 likely understate the benefits of FMNR as they do not account for several important types of income. Livestock production is likely to benefit from the greater availability of fodder resulting from the practice of FMNR, but because livestock in Niger are not confined to the property of their owners but may roam about freely to browse, this benefit will accrue to all livestock owners in the community rather than specifically to FMNR adopting household. Additionally, the income figures reported here do not include the value of non-timber forest products such as edible leaves and fruit. While many households reported receiving such benefits from their trees, most of these products were consumed directly by the household and the survey data did not produce reliable information as to the quantity and value produced.

Households who practice FMNR have more trees per hectare of farmland and a greater diversity of tree species than nonpractitioners. FMNR adopters have about 44 trees per hectare representing 9 different species compared to about 29 trees per hectare representing seven different species for their matched non-adopters. The composition of trees managed under FMNR seems to be dominated by three main species, Faidherbia albida, Bauhinia reticulata, and Guiera senegalensis, all three of which are found in the fields of over half the households surveyed.

We cannot draw firm conclusions about the impact of FMNR on food security based on the four proxy variables used in this study. FMNR does not appear to increase cereal yields or reduce the number of months of perceived food shortage, but it does seem to increase both crop diversity and probably migration rates. Increased income without reducing the number of months a household experiences difficulty finding enough to eat is a curious and problematic combination of results. One possibility is that the variables used in this analysis are poor proxies for food security, and that better data would show improvements in food security along with income and environmental conditions. Another possibility is that greater income does not necessarily lead to improved food security because of household consumption preferences or the time lag between the moment at which the income gains are realized and the time of year during which food insecurity tends to occur. An FMNR adopting household may have dramatically increased revenues around harvest time, but by the arrival of the next lean season eight or nine months later that surplus might be so widely diffused among the household's extended family that its effects on food security are negligible. Or it may be that households tend to spend the extra revenues in ways that are unlikely to impact food security such as on social events or clothing. Better, more detailed data on household revenues, savings and expenditures over an extended period of time might be useful in understanding these results.

The higher migration rates among FMNR adopting households raises the possibility that the income gains associated with FMNR adoption are used to help finance the travel of household members to towns and cities where work opportunities may be more abundant. In this interpretation, regional migration is less of a response to acute vulnerability or food insecurity than an apparently promising livelihood strategy requiring a certain level of resources for its undertaking. Individuals may wish to migrate in search of work but be unable to do so until they have enough money to pay for transportation to their eventual destination. It may be the case, then, that FMNR adoption may enable more aspiring migrants to avail themselves of the opportunity to seek work in other regions or countries.

Adoption of FMNR appears largely determined by soil type, market access and education. Soil type might influence adoption by providing a different mix of tree species for regeneration, some of which may be more valuable or worth protecting. Additionally, previous studies have shown that trees can have both positive and negative effects on crops, and that the balance of those effects is largely conditioned by environmental conditions (García-Barros and Ong, 2004). Perhaps the competition between trees and crops is more intense in sandy soils, discouraging farmers from allowing trees to grow.

The nonlinear relationship between market distance and FMNR adoption suggests that markets offer both incentives and disincentives for adoption, the balance of which changes with proximity. Positive market incentives such as reduced transaction costs for sales of wood and tree products might be dampened by greater pressure from browsing animals or higher risk of illicit tree cutting or theft. The distance from market where the probability of adoption is greatest, about $15 \mathrm{~km}$, may represent the point at which the balance between incentives and disincentives is most favorable for adoption.

The education level of the head of household could conceivably increase the likelihood of adoption in several ways. Education may 
lead to a better understanding of how to practice FMNR, or a greater openness toward innovation in general. Another possibility is that more educated individuals travel more widely and have experienced greater exposure to novel ideas such as FMNR.

Although formal promotion of FMNR by projects and programs does not appear to have a significant impact on adoption, we caution against concluding that FMNR promotion is ineffective. Formal promotion has occurred over many years, concurrent with an apparent spontaneous spread of FMNR from farmer to farmer by word of mouth (Larwanou et al., 2010). Therefore, the effect of promotion on adoption may be more diffuse than can be easily captured by the rather blunt village-level binary variable used in this analysis. Furthermore, our operational definition of FMNR as both pruning and protection of trees may exclude the effects of programs that emphasized only pruning but not protection.

\section{Conclusions}

This study assessed the extent of FMNR adoption, identified drivers of adoption, and estimated impacts of adoption on household livelihood outcomes. We conclude that adoption is widespread in the region of Maradi and determined in large part by soil type, market access, and the education level of the head of household. Adoption appears to raise household income, increase crop diversity, raise migration rates, and increase the diversity and density of trees on farmland. It has no discernable impact on the yields of cereal crops or the number of months households report having difficulty finding enough to eat.

Despite the apparently insignificant impact of living in a village where an FMNR program has previously operated, we believe these findings make a strong case for continued promotion of FMNR in other regions of the Sahel and around the world. FMNR is a low cost means to enhance rural livelihood outcomes and improve local management of natural resources. FMNR especially merits consideration as a low cost alternative to reforestation efforts that rely on tree planting. A typical farmer already owns all the tools necessary to practice FMNR. The only costs associated with the practice are the time it takes farmers to prune/protect trees and the time and expenses an extension service may incur during the process of teaching and promoting the practice. Moreover, because FMNR requires only the awareness, skills, and will of the farmer, once adopted it does not depend on continued support from programs, projects, or extension services.

FMNR has a particular salience in the context of climate change. The increases in crop and tree diversity at the household level associated with FMNR adoption suggest that adopters, by relying on a more diverse portfolio of livelihoods, may be better prepared to cope with the unpredictable risks of a changing climate. FMNR's great potential as a means of sequestering atmospheric carbon could deliver significant benefits to farmers under a well designed payment for environmental services (PES) scheme (Swallow and Meinzen-Dick, 2009). At the macro level, FMNR has likely contributed to the regional re-greening of the Sahel described above. Mortimore (2010) argues that the Sahel's experience adapting to changes in rainfall from the 1960s to the 1990s, including widespread adoption of FMNR among rural farmers, offers important lessons on promoting adaptive capacity more broadly, chiefly by enabling adaptation at the local level.

This analysis was constrained by the ex post nature of the evaluation and the difficulties of identifying FMNR with precision and consistency. The best way to substantiate the findings of this study would be for future FMNR promotion efforts to design their programs in ways that lend themselves to rigorous program evaluation. Such methods could include, for example, proper collection of baseline data before FMNR promotion and implementing programs according to experimental designs. Finally, the methods used in this analysis did not allow for a sufficient examination of the important role of social institutions in the adoption of natural resource management technologies, which other studies of FMNR have emphasized (Abasse et al., 2009). Future studies would benefit greatly by applying a conceptual framework that more fully accounts for these considerations (e.g. Knox et al., 2002).

\section{Acknowledgements}

The authors are grateful to ICRISAT, Bioversity International, and World Vision Australia for their financial support for this study. Serving in Mission (SIM) lent logistical assistance in Maradi. Abdoulaye Amadou was an invaluable resource during the collection of the field data. Tony Rinaudo, Peter Cunningham, Mahamane Larwanou, and Tougiani Abasse offered crucial insights and feedback based on their many years of FMNR experience. We wish to thank the two anonymous reviewers for their careful reading of the manuscript and their very helpful comments. We owe a special debt of gratitude to the hundreds of rural households in the Region of Maradi who were so generous with their time and personal information.

\section{References}

Abadie, A., Drukker, D., Leber Herr, J., Imbens, G.W., 2004. Implementing matching estimators for average treatment effects in Stata. Stata Journal 4 (3), 290-311.

Abasse, T., Guero, C., Rinaudo, T., 2009. Community mobilisation for improved livelihoods through tree crop management in Niger. Geojournal 74, 377-389.

Adam, T., Reij, C., Abdoulaye, T., Larwanou, M., Tappan, G., 2006. Impacts des Investissements dans la Gestion des Resources Naturelles (GRN) au Niger: Rapport de Synthese. Centre Régional d'Enseignement Specialise en Agriculture (CRESA). Niger, Niamey.

Boffa, J.M., 1999. Agroforestry parklands in sub-Saharan Africa. FAO Conservation Guide 34.

Caliendo, M., Kopeinig, S., 2008. Some practical guidance for the implementation of propensity score matching. Journal of Economic Surveys 22 (1), 31-72.

CIMMYT, 1988. From Agronomic Data to Farmer Recommendations: An Economics Training Manual. Completely Revised Edition. International Maize and Wheat Improvement Center (CIMMYT), Mexico, D.F.

Cunningham, P., Abasse, T., 2005. Reforesting the Sahel: farmer managed natural regeneration. In: Kalinganire, A., Niang, A., Kone, A. (Eds.), Domestication des espèces agroforestières au Sahel: situation actuelle et perspectives. ICRAF, Nairobi ICRAF Working Paper.

Dugan, P., Durst, P., Ganz, D., McKenzie, P. (Eds.), 2003. Advancing Assisted Natural Regeneration (ANR) in Asia and The Pacific. FAO Regional Office for Asia and the Pacific, Bangkok RAP Publication 2003/19.

Farrington, J., Carney, D., Ashley, C., Turton, C., 1999. Sustainable livelihoods in practice: early applications of concepts in rural areas. Natural Resource Perspectives 42. ODI, London.

Friday, K.S., Elmo Drilling, M., Garrity, D.P., 1999. Imperata Grassland Rehabilitation Using Agroforestry and Assisted Natural Regeneration. International Centre for Research in Agroforestry, Southeast Asian Regional Research Programme, Bogor, Indonesia.

García-Barros, L., Ong, C.K., 2004. Ecological interactions, management lessons and design tools in tropical agroforestry systems. Agroforestry Systems 61, 221-236.

Gönner, C., Haug, M., Cahyat, A., Wollenberg, E., de Jong, W., Limberg, G., Cronkleton, P., Moeliono, M., Becker, M., 2007. Capturing Nested Spheres of Poverty: A Model for Multidimensional Poverty Analysis and Monitoring. CIFOR Occasion Paper No. 46. Centre for International Forestry Research, Jakarta, Indonesia. $24 \mathrm{p}$.

von Grebmer, K., Fritschel, H., Nestorova, B., Olofinbiyi, T., Pandya-Lorch, R., Yohannes, Y., 2008. The Challenge of Hunger: The 2008 Global Hunger Index. International Food Policy Research Institute (IFPRI), and Concern Worldwide, Welthungerhilfe.

Harris, R., 2007. Niger's trees may be insurance against drought. Video report, National Public Radio, Washington, DC. Available from: http://www.npr.org/ templates/story/story.php?storyld $=11608960$.

Herrmann, S.M., Anyamba, A., Tucker, C.J., 2005. Recent trends in vegetation dynamics in the African Sahel and their relationship to climate. Global Environmental Change 15, 394-404.

INS (Institute National de la Statistique du Niger), 2008. Available from: http:// www.stat-niger.org/ (accessed June 16, 2009).

IMF, 2008. World Economic Outlook Database. Available from: http://imf.org/ external/pubs/ft/weo/2008/02/weodata/index.aspx (accessed April 14, 2009).

Joet, A., Jouve, P., Banoin, M., 1998. Le défrichement amélioré au Sahel: Une pratique agroforestière adoptée par les paysans. Bois et Forêts des Tropiques 255, 31-44. 
Knox, A., Meinzen-Dick, R., Hazell, P., 2002. Property rights, collective action, and technologies for natural resource management: a conceptual framework. In: Meinzen-Dick, R., Knox, A., Place, F., Swallow, B. (Eds.), Innovation in Natural Resource Management: The Role of Property Rights and Collective Action in Developing Countries. The Johns Hopkins University Press, Baltimore, MD.

Larwanou, M., Abdoulaye, M., Reij, C., 2006. Etude de la Régénération Naturelle Assistée dans la Région de Zinder (Niger). USAID/EGAT and IRG. 48 p..

Larwanou, M., Oumarou, I., Snook, L., Danguimbo, I., Eyog-Matig, O., 2010. Pratiques sylvicoles et culturales dans les parcs agroforestiers suivant un gradient pluviométrique nord-sud dans la région de Maradi au Niger. Tropicultura 28 (2), 115-122.

Levett, C., August 13, 2008. Under The Shifting Sands, A Blessing for The Desert. Sydney Morning Herald.

Mortimore, M., 2010. Adapting to drought in the Sahel: lessons for climate change. Climate Change 1 (1), 134-143.

Mukherjee, C., White, H., Wuyts, M., 1998. Econometrics and Data Analysis for Developing Countries. Routledge, London.

Olsson, L., Eklundh, L., Ardö, J., 2005. A recent greening of the Sahel-trends, patterns and potential causes. Journal of Arid Environments 63, 556-566.

Pattanayak, S., Mercer, D., Sills, E., Yang, J.-C., 2004. Taking stock of agroforestry adoption studies. Agroforestry Systems 57 (3), 173-186.

Pender, J., Ndjeunga, J., 2008. Assessing Impacts of Sustainable Land Management Programs on Land Management and Poverty in Niger: Report II. International Food Policy Research Institute, Washington, DC. Mimeo.
Polgreen, L., 2007. Niger, trees and crops turn back the desert. New York Times Feb. 11 Rinaudo, T., 2007. The development of farmer managed natural regeneration. Leisa Magazine 23 (2), 32-34.

Reij, C., Tappan, G., Smale, M., 2009. Agroenvironmental transformation in the Sahel: another kind of "Green Revolution". IFPRI Discussion Paper 00914 International Food Policy Research Institute, Washington, DC.

Rosenbaum, P.R., Rubin, D.B., 1983. The central role of the propensity score in observational studies for causal effects. Biometrika 70 (1), 41-55.

Salopek, P., 2008. Lost in the Sahel. National Geographic April.

Scoones, I., 1998. Sustainable Rural Livelihoods: A Framework for Analysis. Institute for Development Studies, Brighton, UK. Working Paper 72.

Swallow, B., Meinzen-Dick, R., 2009. Payment for environmental services: interactions with property rights and collective action. In: Beckmann, V., Padmanabhan, M. (Eds.), Institutions and Sustainability. Springer, Dordrecht, The Netherlands.

UNDP, 2007. Human Development Report 2007/2008: Fighting Climate Change: Human Solidarity in A Divided World. Palgrave Macmillan, New York.

UNDP, UNEP, World Bank, World Resources Institute, 2008. World Resources 2008: Roots of Resilience - Growing the Wealth of the Poor. July. Available from: http://www.wri.org/publication/world-resources-2008-roots-of-resilience (accessed April 10, 2009).

USAID, CILSS, IRG, 2002. Investir dans la Forêt de demain: vers un programme de révitalisation de la foresterie en Afrique de l'Ouest. Washington/Ouagadougou. 